\title{
SOME RECENT DEVELOPMENTS IN SCHOOL HYGIENE.*
}

\author{
BY ALFRED GREENWOOD, M.D., D.P.H.,
}

Medical Officer of Health and Medical Officer to the Education Committee, Blackburn.

Tre passing of the Education Act of 1902, and the consequent administrative measures, have given prominence to many questions of a special interest to Medical Officers of Health.

Many of these officials have been appointed also as Medical Officers to Education Authorities, and the number of medical gentlemen responsible to both the Health and Education Committees in various towns is increasing steadily.

During the last three years numerous reports have been written by these Officers which have drawn attention to certain defects in school life, both structural and personal. Also recent reports have been issued by Government Departments, notably the following :-

1. Reports on Children under Five Years of Age in Public Elementary Schools by Women Inspectors of the Board of Education, and

2. The Report of the Inter-Departmental Committee on Medical Inspection and Feeding of Children attending Public Elementary Schools.

In this paper I have considered school hygiene in its widest sense.

Regarding the attendance at school of children between the ages of three and five years, I believe there is a consensus of opinion that they do not obtain any educational advantages over the children of those ages who are kept at home until after the age of five.

Also it has been shown that children who attend school for the first time after the age of five years have no difficulty in " making up for" lost educational time. Indeed, they are generally more original in speech and action than younger children who have devoted the previous twelve or eighteen months mainly to copying and verbal repetition.

There is no doubt that the exclusion from school of children under five years would result in a greatly diminished incidence and mortality from infectious diseases, especially measles. There are, however, other points to be considered before this step can be recommended

* A paper read before the North-Western Branch of the Incorporated Society of Medical Officers of Health, at a meeting held in Manchester on December 15th, 1905. 
universally. For instance, what would happen in a town like Blackburn if this were carried into effect? There are in Blackburn 23,869 female cotton employees, of whom 8368 are married or widowed, and about 3000 children below the age of five years attend the public elementary schools of that town.

A large number of these houses are locked up during school hours, and frequently the only person responsible for the key of the house is a girl aged ten or twelve years who is attending the mixed or girls' department of the same school. Children under five could not be left in a house without the supervision of an older person.

Therefore Local Education Authorities in towns of this kind could not exclude all these children from school unless they provided crèches.

And in my opinion the difficulty regarding the spread of infectious diseases would be practically as great in crèches as in schools.

It is possible that the same difficulty does not occur in rural districts as in busy manufacturing towns.

Therefore $I$ believe the prudent and scientifie advice which should be given in this very important matter should discourage the attendance at school of children between the ages of three and five years whose parents are at home and able to look after them, and should allow school attendance for these young children if their parents are away at work during the day.

At the same time the greatest care should be taken that the conditions under which these children attend school should be ac healthy and free as possible. They should not be wearied by monc tonous lessons, or long periods of sitting or standing still. Thei teachers should be trained to detect children who are physically $i$ or who may be commencing with any of the infectious diseases, anu especial attention should be given to all sanitary conditions, such as ventilation, heating, lighting, etc.

In the Introductory Memorandum of the Report of the Board of Education on Children under Five it is stated that "these little children should have no formal instruction in the three $R$ 's, but plenty of opportunities for free expression: they must learn to talk before they learn to read; to understand before they learn numbers by heart; and to use arms and fingers freely and boldly before they hold pen or pencil to trace letters. Needlework is bad for little eyes and cramps little fingers."

Further, although kindergarten teachers are praised, so-called kindergarten occupations are condemned as being contrary to the 
spirit of Froebel when taught mechanically to large classes. "They are often," says one Inspector, "distinguished by absence of occupation for the children do a line or a stitch or add a brick by word of command, and then sit still for five minutes while the teacher goes round the class to ensure perfect accuracy; meanwhile all interest is lilled in the child, who may only touch his material to order."

"No formal instruction" is the burden of all the recommendations of the lady inspectors, but more play, more sleep, more free conversation, story-telling, and observation.

Those pupil teachers who are intending to teach in Infants' Departments should receive a special training applicable to the supervision of the younger children. Fortunately, there is now a tendency to diminish the size of the classes, and less stress is laid upon the educational results amongst infants than formerly.

Such dangers as long periods of sitting still, shortened playtimes, lack of differentiation between a school time-table for infants and for the older scholars, insufficient exercise, and unsuitable lessons, are disappearing rapidly.

Nurses have been appointed by the Education Committees of London and other large towns, for the purpose of inspecting children for ringworm and other skin diseases. This has been a very successful experiment, and no doubt the scope of such work will probably be widened in the near future. Also medical inspection of school children is receiving more attention every year.

Recently a large number of sanitary defects have been remedied in many schools of this country.

So that altogether it may be expected with confidence that the lot of the young child at school in future will be more happy and free than it has been in the past.

The feeding of school children is a question which has recently excited great attention on the part of medical men and the public generally.

In the reports of children under five years of age the Women Inspectors of the Board of Education appear to agree that it is unsuitable rather than insufficient feeding which is responsible for sickly children, and that want of sufficient sleep, neglect of personal cleanliness, badly ventilated homes, are contributory causes of the low physical standard reached.

The Inter-departmental Committee on "Medical Inspection and Feeding of Children attending Public Elementary Schools" found forty-eight Authorities under Part III of the Education Act 
of 1902 , in addition to London, in whose areas a definite system of medical inspection has been established. These forty-eight areas comprise two counties, twenty-five county boroughs, ten boroughs, and eleven urban districts.

The report of that Committee states that not infrequently the Medical Officer of Health has been appointed Medical Officer to the Education Committee, and that this arrangement has many conveniences as it has often been the outcome and development of the work done by the Medical Officer of Health in visiting the schools for the prevention of the spread of infectious disease.

Medical Officers for educational purposes have been appointed by six counties, thirty-one boroughs, and thirteen urban districts.

As I called attention to the desirability of the School Medical Officer and the Medical Officer of Health being the same official, in my paper before you last year, it may be of interest if I quote the remarks of the above-named Committee on this subject.

"The duties of the two offices naturally overlap, or may do so. The inspection of children for the prevention of the spread of infectious disease and the sanitary inspection of the premises are examples of this. The union of the two offices tends to prevent duplication of work. It has the additional advantage that the staff of the Authority's Sanitary Department is thus made easily accessible for any special work. They are employed for disinfecting schools, and for following up cases of dirty and verminous children, and for obtaining attention to the condition of the homes as well as of the children. At the same time the Medical Officer of Health finds that his position as Educational Medical Officer greatly facilitates his work in preventing the spread of infectious disease. The chief danger of the arrangement is that the work for the prevention of infectious disease may tend to swamp the work in other directions."

The Committee have also referred to the difficulties of a School Medical Officer who is also in private practice.

The results of medical inspection of school children hitherto carried out have been set forth by the Committee in seven paragraphs.

These may be summarized as follows :-

I.-The establishment of proper organizations for the prevention of the spread of infectious disease, which includes increased knowledge on the part of teachers and prompt action. In no small measure is this due to the combination of the Sanitary and Educational Authorities by the Education Act of 1902 .

II.-The results of greater cleanliness of school children, and measures for the prevention of ringworm. 
III, IV \& \& V.- The attention paid to defective children and impaired vision, with the supply of surgical apparatus and spectacles as a result. Also defective hearing is being dealt with.

VI \& VII.-The increased interest of the teacher in the physical welfare of the children, which has frequently resulted in the treatment of defects, and the more strict supervision of the light, ventilation, and sanitary condition of school buildings.

There is no doubt that many improvements in the above respects are still needed, but a beginning has been made, and if the useful work is continued valuable results cannot but ensue.

It may be of some interest if I refer to a special investigation carried out in Blackburn this year in order to ascertain the extent of underfeeding amongst the school children of that town. This enabled me to make a definite statement as to the extent of this evil; which is more trustworthy than opinions which have been expressed upon general impressions only.

The enquiry was a very delicate one, and required much tact, patience, and discrimination. There were several difficulties, such as the unwillingness of many people to supply information as to the addresses of families where underfeeding was suspected; the hesitation of some parents in answering questions of a private nature, such as income and expenditure; the difficulty of obtaining accurate information regarding habits of parents, etc., etc.

The first object was the collection of a list of houses in which it was suspected there might be underfed or neglected school children. For this purpose special enquiries were made from school teachers, school attendance officers, police and sanitary inspectors, and officials of voluntary agencies for supplying meals. Very great attention was given to houses with the prefix "Back." In all, 540 such addresses were supplied to me. The houses were then visited, and in order that the results of these enquiries might be uniform I drew up the following form (shown on page 380), which appears to cover the essential points, and which was filled up at each of these 540 houses which were situated in 249 different streets of the town.

On analysing the results of my enquiries into the 540 houses which I had ascertained, in the manner described above, might possibly contain underfed school children, I was able to state that at 364 of these houses there was no underfeeding of the children.

I was able to make this statement from a knowledge of the wages of the family, the habits of the parents, condition of the homes and inmates, and the general circumstances of the family. In many of 
Name of School

UNDERFEd ChILdREN.

Date of Visit

Underfed Children.
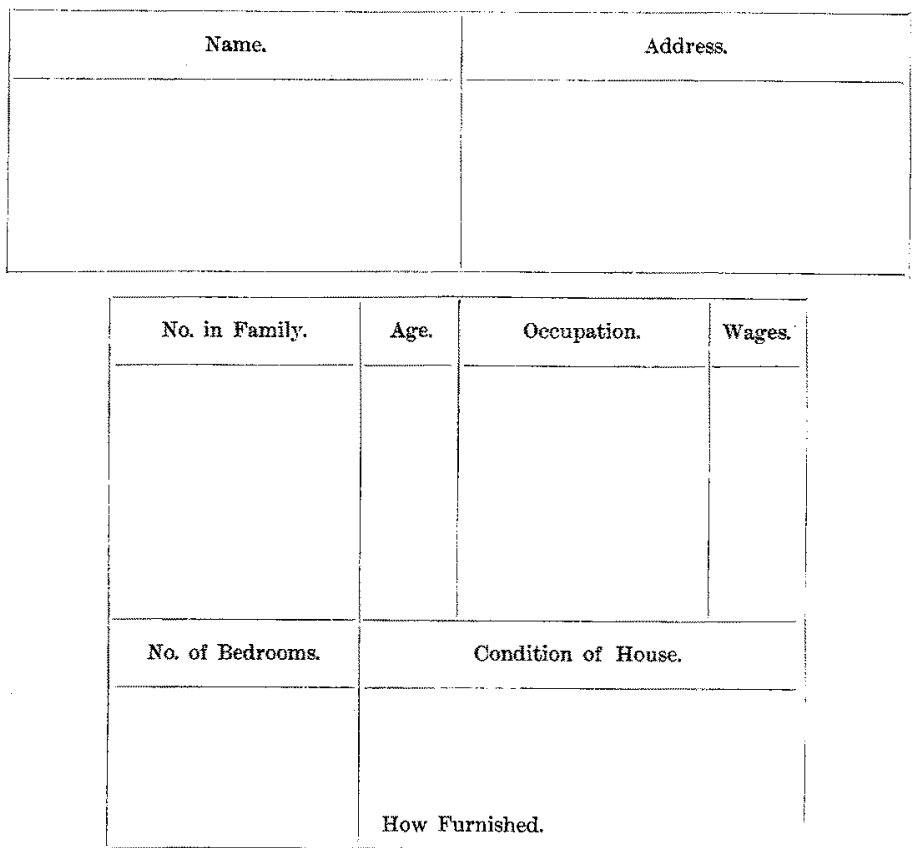

Rent of house and other outgoings )

other than for clothes and food)

Attendance at School-

Regular

Irregular

Condition of child or children on visit

Has any relief (Public or Private) been received

Officer's private opinion as to cause of underfeeding-

(a) Illness of child

(b) Medical attendance

(c) Inability of parents to work or obtain work

(d) Habit of parents-Laziness, Alcoholism

(e) If father out of employment, ) last time he received any remuneration

Any other remarks. 
these cases the ineome of the family is $£ 4$ or $£ 5$ per week. Amongst these 364 families were a certain number of children who were neglected but who were not underfed.

The results of the enquiries at the remaining 176 houses were divided into the following three groups of cases.

I.-Those cases which may be underfed owing to permanent impoverishment of the parents.

II.-Those cases which may be underfed owing to temporary illness, loss of employment, or other unavoidable causes which have rendered the parents incapable of making necessary provision for the children.

III.-Those cases which may be underfed owing to neglect on the part of parents capable of making this provision.

In the descriptions of cases an attempt was made to indicate those families in which underfeeding is probable when trade is bad and when the weather is severe. Also I have included children from the ages of three to fourteen years inclusive.

I have relied upon the statements of the father or mother as to the amount of earnings in each family. Individual verification was not possible, but in such a town as Blackburn, where so many sets of wages are similar, it was not difficult to judge whether or not the majority of these statements were truthful.

I regret that time did not allow me to weigh and measure the underfed children.

The results of the above enquiry are interesting. Ninety-seven families were found in which underfeeding was taking place at the time of the investigation, or in which underfeeding is probable under certain conditions. These 97 families included 313 children from the ages of three to fourteen years inclusive.

A total of 22,952 children are attending the various departments of the public elementary schools of Blackburn.

Therefore, even based on the rigorous standard mentioned above, it is probable that not more than $1 \cdot 3$ per cent of the Blackburn school children suffer from underfeeding.

Accordingly, I expressed the opinion that the various voluntary agencies which at present exist in Blackburn are able to cope with this evil.

At the same time it appears desirable that an Education Authority should have information as to the extent of poverty amongst school children, and the existing help given, so that they may have an opportunity of making such suggestions as appear to them to be desirable, and of supervising the organization generally. 
All will agree that underfed children who are attending school are unfitted for lessons either mental or physical. Such children are liable to contract boils, ophthalmia, etc., and are an easy prey to any infectious diseases which are peculiar to school life.

Underfeeding is associated frequently with a dirty condition of the body, and with insufficient clothing, although I have seen children who were underfed and yet clean and tidy. Also a dirty child is a frequent sign of a dirty home.

The causes of underfeeding appear to be divisible into those causes which are beyond the power of the parents, and those causes which they can avoid.

Amongst the causes beyond the power of the parents which transpired during my enquiry, may be mentioned the following: Ill-health of the father, who was in many cases the only bread-winner of the family. In some cases the father was a cripple, either through accident or disease, and in other cases he was suffering from such diseases as phthisis, diabetes, heart disease, etc. This condition of affairs, of course, is made worse if there is a large family of young children, and in many cases, where the father's wage is insufficient, the mother is compelled to earn money either in the mill or by washing. In its turn, this necessitates a lack of supervision over the young children left at home, or the mother is compelled to pay a sum varying from $4 \mathrm{~s}$. to $8 \mathrm{~s}$. weekly to another woman who looks after the children during the absence of the parents. This arrangement is often unsatisfactory.

In another series of cases the father is an outdoor labourer, which involves a risk of loss of wage during severe climatic conditions, and in a large number of homes the wage is not so great as to enable the parents to save a little money for "a rainy day."

I was much impressed by the large number of families who pay weekly sums, varying from $6 \mathrm{~d}$. to $2 \mathrm{~s}$. $6 \mathrm{~d}$., in burial clubs. In some cases it must have been a great tax for the family to pay "the weekly club money." I was also struck by the fact that many mothers in poor circumstances and with six or eight children were again pregnant.

Certain families appeared to be paying a higher rent than they could afford in comparison with others. In a number of cases the parents were unwilling to apply for poor-law relief, and others had suffered considerably before asking for such relief. Many deserving families had received generous help from their neighbours who were situated more fortunately.

In many houses it seemed there is a brighter prospect, as the children 
are growing up and reaching the wage-earning age, and whatever may be said either for or against "the half-time system," some families would be in greater need if the "half-timers" were not earning any money.

Amongst the causes of underfeeding which are within the control of the parents may be mentioned alcoholism, laziness, indifference, and bad management. It is obvious that in those families where there is a tendency to poverty, the distress is greater when the parents possess these habits.

I would recommend strongly that wilful neglect on the part of parents causing underfeeding of the children should be met by very severe measures, such as prosecution.

I am sure that considerable waste occurs in many homes through a lack of knowledge as to cheap, nutritious articles of diet, and economical cooking. In other words, "the money might be made to go farther " in some families.

It is important that the elder girl scholars should be taught the preparation and cooking of such meals as are available in a working man's home. This is more important than a knowledge of the preparation of "fancy dishes."

On April 26th, 1905, the Local Government Board issued an Order called "The Relief (School Children) Order, 1905," to the Poor Law Guardians in England and Wales.

In this order it is stated that it is the duty of the Guardians to give relief to any child which is without food, and it is possible to recover from the father the cost of such relief given to the child. There does not appear to be in this Order an equal facility for the destitute children of widows.

It is to be hoped that this order will not interfere with the voluntary agencies which already exist for feeding children.

Cases of distress from permanent poverty appear to be suitable for treatment by the Guardians.

Special help is necessary in many cases of distress due to temporary loss of work, etc.

Needless to say, the most careful enquiry should be made into every case.

Regular feeding, of course, is preferable to the provision of meals for one or two days per week.

Care should be taken, on the one hand to avoid any undue pauperization of parents, and on the other hand to avoid any measure which will diminish the parental responsibility. 
Amongst the recommendations made by the Inter-departmental Committee on Physical Deterioration, appointed in September, 1903, are several relating to school children apart from their medical inspection and feeding, namely, instruction in cookery, hygiene, domestic economy, and special schools.

Also the giving of special grants by the Board of Education for instruction in cookery, laundry work, dairy work, cottage gardening, manual instruction, and household management, are examples of attempts to instil sound practical knowledge into the minds of school children.

Again, the Inter-departmental Committee on Physical Training have drawn up a new syllabus of physical exercises which will probably gradually supplant the model course issued in 1902.

Useful work has been initiated and is being continued by local education authorities in the teaching of swimming to school children, and in encouraging them by prizes to cultivate plants in flower-pots at their own homes.

Other developments which have a more indirect bearing on school hygiene consist in circulating school libraries, distribution of these books by teachers, school classes at libraries and museums, cooperation between libraries and school teachers, closer association between parents and teachers, popular lectures, etc.

The foregoing are a few instances of recent developments in school hygiene, both local and general, which indicate that supreme efforts are being made to guard zealously the mental and physical welfare of children of school age, and which assuredly will bear fruit in coming years.

Notification of Measles.- In his annual report for 1905 the Medical Officer of Health for the Pontypool Rural District states that he does not consider much advantage has been gained by the compulsory notification of measles in the district.

Copper Sulphate and Water Purification.-Mr. H. Watkins Pitchford, the Government bacteriologist and analyst of Natal, concludes that 1 part of copper sulphate n 100,000 parts of water is sufficient to destroy the ordinary bacterial flora of running water if allowed to act upon it for twenty four hours; and that 1 part of the copper sulphate in 75,000 parts of water-i.e, about a grain per gallon is sufficient, according to his observaions, to destroy the vitality of the typhoid bacillus in an infected water with exposure of three hours. It would be well, however, that before any attempt is made to purify water in this manner on a large scale, as when a community is affected by typhoid fever, the statement of the alleged innocuousness of traces of copper salts should be very carefully examined. 